\title{
INNOVATIVE AND TECHNOLOGICAL POTENTIAL AS A NECESSARY CONDITION FOR THE SUSTAINABLE DEVELOPMENT OF THE REGION
}

\author{
Daria Londarenko'
}

\begin{abstract}
The object of the study is regional economic systems that implement innovative technological processes. The subject of the study is the economic, organizational, and managerial relations that develop in the process of formation and use of innovative and technological potential at the regional level. The purpose of the article is to study the innovative potential of the regions, substantiate the theoretical provisions and develop methodological recommendations for the development of effective ways and forms of its mobilization. Methods. The theoretical and methodological basis of the study is the conceptual provisions and scientific developments of domestic and foreign scientists on the formation and use of elements of innovative and technological potential at various levels of management, published in monographs, periodicals and materials of scientific and practical conferences on the topic of research. The study is based on a general scientific methodology that provides for the use of a systematic approach. Methods of observation, comparison, categorical, structural-functional, situational, economic mathematical methods, and the method of hierarchy analysis are used to solve the tasks. Results. The article describes the innovative and technological potential of the region as an economic and managerial category. The typology of innovation as a complex and diversified concept containing many interacting components is studied. The following essential characteristics of the innovation and technological potential of the region are highlighted. Firstly, the innovative and technological potential of the region is determined by the opportunities available to it for change. The innovation potential creates conditions sufficient to ensure the progressive development of the regional socio-economic system through the creation of innovations and their purposeful transformation into innovations. Secondly, the innovative and technological potential of the region is characterized by the presence of specific ones, both involved and not involved in production, but prepared for use in it. Third, the innovative and technological potential of the region is determined by the willingness to use the existing innovative opportunities in order to translate innovations into innovations. The structure of the innovation and technological potential of the region is studied. It is determined that of all the components of the innovation potential of the region, the most important is the labor (human) potential. It is characterized, firstly, by the level of qualification, intelligence, and creativity of the population living and functioning in the territory. It is the population, on the one hand, that is able to produce innovations, and on the other hand, to introduce and distribute them, thereby determining the opportunities and directions of innovative development. It is highlighting innovative and technological potential of the region following components, including the capacity of: organization and management technology; research and development; marketing; technology and production; personnel; potential financial base; knowledge base; natural resource. Practical value. This classification of the components of innovation and technological potential is of great practical importance. It focuses the attention of researchers and users on the simple fact that the key element of the innovation potential of the region is the subjects of innovation activity operating on its territory. In particular, among all subjects of management, both employed and not employed population in the market sector of the economy should be singled out.
\end{abstract}

Key words: technopolis, regional economy, innovative infrastructure, economic regulation, clustering, high-tech company, innovation and technological modernization, scientific and technical development.

JEL Classification: R11, F63

\footnotetext{
Corresponding author:

${ }^{1} \mathrm{PE} \ll$ GALAEXPERT $\gg$, Ukraine.
} 


\section{Introduction}

The process of adaptation of socio-economic systems to a dynamically changing external environment in modern conditions is largely determined by the ability to timely find and use competitive success factors as productively as possible. This process is directly dependent on the ability to continuously develop and improve. Innovative and technological potential are becoming the main engine of progress and a condition for the sustainable functioning of regional socioeconomic systems. This conclusion is confirmed by the assessment of the development results of countries that have created an innovative economy, in other words, an economy based on knowledge and information technologies. The truth of these provisions is determined by the main properties of the category "innovative economy": the innovative economy is a continuous process of improvement and the emergence of fundamentally new ideas, inventions, which, as they accumulate, develop into new breakthrough innovations; in an innovative economy, knowledge plays a crucial role, and the production of knowledge is a source of growth; the innovation economy is based on information, as well as information and communication systems, space and the use of the Internet in all spheres of human activity.

The concept of innovation, which underlies the innovation economy, covers all aspects of human life and means innovation that improves human life. Innovation is a renewal, transformation of activity, which leads to the replacement of some of its elements with other, more advanced ones. Initially, they are formed in consciousness as a problem associated with the presence of a contradiction between reality and a possible state. Ultimately, innovations are manifested because of differentiation of interests of market participants and involve the resolution of existing contradictions through targeted activities.

\section{Typology of innovations}

Innovation is a complex and diversified concept that contains many interacting components. Innovation defines changes in the properties and performance characteristics of the product as a whole and changes in the components of the product that increase its effectiveness, including the nature of the services that provide them. In this regard, the validity of the methodological approach adopted by us is confirmed by the generally accepted list of types of innovations:

- introduction of a new product or qualitative change in an existing product;

- a process innovation that is new to the industry;

- opening of a new market;

- development of new sources of supply of raw materials or other investments;

- changes in the business organization.

From the point of view of managing the innovation process, it is important to take into account the existing typology of innovations. Traditionally, there are innovations that allow you to create new products or those for creating new technologies. Depending on the level of novelty, they are divided into basic and secondary. In the modern sense, basic innovations imply a radical change in the technological base and methods of organizing production, the sociocultural sphere. Secondary innovations are aimed at the development and modification of basic innovations, their dissemination in various fields. Among the technological innovations, experts also distinguish imitations that repeat already developed innovations, and innovations that are implemented for the first time. In the spatial sphere, global, civilizational, national, regional, local and point innovations are distinguished. Complementing the typology, it is proposed to subdivide innovations into ascending ones related to scientific research, and descending ones related to the process of commercialization of scientific achievements.

This list could be continued, but within the framework of the task, the above definitions are sufficient to draw the following important conclusion: the typology of innovation potential, which characterizes the conditions and opportunities for innovation activity, is adequate to the typology of innovation.

The multidimensional nature of the category "innovation" is the basis for resolving constantly emerging contradictions both within socioeconomic systems and in their relationship with the environment, in other words, the basis for the sustainable development of socio-economic systems.

In our opinion, to ensure a high level of competitiveness of socio-economic systems, it is necessary, on the one hand, to have a powerful innovation potential, on the other hand, to use it productively. Both sources should be considered as the root causes of innovation activity at the level 
of the socio-economic system for the following reasons.

Firstly, the development of innovation activity in the region occurs as a reaction not to everyone, but only to the "technological push" that is adequate to the accumulated innovation potential. In other words, if the region does not have the necessary conditions and opportunities to create innovations in a particular area where there is a "technological push", then it is impossible to expect adequate innovation activity.

Secondly, information about the needs of society is a kind of push to find technical opportunities to meet them. This means that public choice, public preferences expressed through the ratio of supply and demand form the priorities of innovation in socio-economic systems. However, the statement about the linear dependence of the process of innovation and demand means a serious simplification of this problem.

Simultaneously with the formation of innovative priorities, there is an improvement and development of mechanisms that allow flexibly to combine the directions of scientific research ith the needs of society. The potential of the whole set of these factors is contained in the innovative potential of the subjects of innovative activity, whether it is an individual, an enterprise, a region, or a country as a whole.

\section{Characteristics of the innovative and technological potential of the region}

Within the framework of our research, the problem of the development and use of the innovative potential of the region is of exceptional interest. The innovative potential of the region is an independent system category, along with the production, economic, human, organizational and information potential, it is part of the potential of the region. The interaction of these independent system categories forms a synergistic effect of the region's activities and sustainable development.

The innovative and technological potential of the region as an economic and managerial category is currently poorly studied, in our opinion; it is the main one in the system of the total potential of the region. In this regard, it should be noted that in the above-mentioned review of the main terms and definitions, the category of "innovation potential" is not considered at all. Meanwhile, the development of theoretical provisions, assessment methods and recommendations for the management and use of the innovative potential of the region will help the authorities to navigate in a changing and contradictory environment, developing a set of adequate measures to ensure the sustainable development of the region.

Thus, the study of the above definitions of innovation potential, as well as the innovation potential of the region, allows us to draw the following conclusion. In their definitions, the authors focus on such characteristics of potential as "capabilities", "resources", "readiness" and "ability".

Note that "opportunity" is a general concept that includes both private concepts such as" resources" and "ability".

Therefore, in our opinion, the innovative potential of the region is the opportunities available to it and the readiness to produce and / or use innovations in this territory or beyond its borders that ensure its sustainable social, economic and environmental development.

The innovative opportunity includes available prerequisites for the implementation of the changes. Various reasons can serve as an incentive that encourages a business entity to change.

There are two types of changes: change because of innovation and change as a source of innovative opportunities. It should be noted here that changes as a source of innovative opportunities are determined by the totality of all changes in the internal and external environment of the region.

Thus, the following essential characteristics of the innovation potential of the region can be distinguished:

Firstly, the innovation potential of the region is determined by the opportunities for change at its disposal. The innovation potential creates conditions sufficient to ensure the progressive development of the regional socio-economic system through the creation of innovations and their purposeful transformation into innovations.

Secondly, the innovative potential of the region is characterized by the presence of specific ones both involved and not involved in production but prepared for use in it.

Thirdly, the innovative potential of the region is determined by the willingness to use the existing innovative opportunities in order to translate them into innovations.

The innovative potential of the region can be characterized, on the one hand, by the achieved level of its socio-economic development, on the other hand, by the possibilities of ensuring its further 
growth. Three groups of dependencies determine the magnitude and dynamics of changes in the innovation potential of the region: quantitative and qualitative characteristics of the components of the potential; relationships between subsystems (system quality); interaction of external factors.

Innovation potential can be large from a quantitative point of view, that is, include significant material, technical, information, labor and other resources, but not used, and therefore do not have a significant positive impact on economic development. The potential may be high in terms of quality, but it may not correspond structurally to the needs of regional development. It is important to keep in mind that potential is only an opportunity that may not be used.

\section{The composition and structure of the innovation and technological potential of the region}

The composition of the innovative potential of the region in the economic literature is presented in different ways. The most common description of the innovation potential is the following, which includes:

- natural resources;

- state of the environment;

- population, its gender and age composition and general education level, labor resources, level and dynamics of employment;

- production potential (fixed capital, the level of its depreciation, the technological and reproductive structure of fixed capital, the level of specialization and technological equipment, the competitiveness of products);

- scientific and labor potential (the assessment of the resource, technological and human resource base, R \& D results of scientific and innovation activities, the scope of progressive, traditional and high-technology-oriented activities);

- regional and geopolitical aspects of innovation potential (differentiation of levels of economic development, natural and climatic differences, the level of anthropogenic load by region);

- regional infrastructure (transport, communications, services, etc.).

Natural resource potential of the region, the achieved level of economic and technological development of society and the study areas used in economic and other human activities, on the one hand, create conditions for implementation of innovative activities and, on the other hand, are the permanent object of innovation. The availability of natural resources, firstly, affects the formation of the territorial structure of the economy; secondly, it affects the industry specialization of the region; thirdly, it affects the pace of district (regional) socio-economic development; fourthly, it helps to increase the role of the region in the commodity market.

Of all the components of the innovation potential of the region, the most important is the labor (human) potential. It is characterized, first of all, by the level of qualification, intelligence, and creativity of the population living and functioning in the territory. It is the population that is able, on the one hand, to produce innovations, and on the other hand, to introduce and distribute them, thereby determining the opportunities and directions of innovative development.

It is distinguished by the allocation of the following components in the innovation potential of the region, including the potential of:

- organizations and management technologies;

- research and development;

- marketing;

- technology and production;

- personnel;

- potential of the financial base;

- information base;

- natural resource.

The significance of this approach lies in the fact that it creates a basis for the practical use of each of the elements of innovation potential by management stakeholders. Thus, the use of the potential of marketing acts as an objective need to focus the scientific and technical, production and sales activities of the company on taking into account market demand, needs and requirements of consumers.

The potential of the organization and management technology represents the ability and readiness of the region to use innovative opportunities in the field of values, standards of behavior and traditions, worldview features of the region, centralization and decentralization, methods and procedures for monitoring the implementation of decisions, management information systems, organization of the communication system, management style, qualifications and abilities of senior management, strategic planning systems in the region. This element of innovation potential is currently being emphasized, since it is the introduction of innovations that is the most vulnerable stage in 
the organization of the innovation process in our country.

The potential of research and development in the region characterizes the ability and willingness of the region to use innovative opportunities composition of personnel engaged in research and development, their qualifications and experience, motivation, condition of laboratory facilities and test equipment, cooperation with other regions, licensing agreements, and organization of the design process.

Marketing potential of the region - the ability and readiness of the region to use innovative opportunities regarding the applied concepts and strategies, sales markets, consumers, products, pricing policy, distribution channels, sales organization, sales agents, inventory of goods, trade costs, after-sales service, advertising activities in the region.

The potential of technology and production of the region is the ability and readiness of the region to use for innovative purposes production units, technologies, fixed assets, organization of maintenance, production, scheduling system, organization of quality control.

Personnel potential of the region is the ability and willingness of the region to the use of staff competencies and skills, HR policy, training, and professional development, rating system, payment and work motivation. The potential of personnel in the regions of Ukraine in the current conditions remains very high, and often exceeds the same indicator of developed countries. This is especially true for the engineering staff of employees who have a high degree of sensitivity to innovation and qualifications, as well as a wide range of tasks that can potentially be effectively solved by these specialists.

The potential of the financial base of the region is the ability and readiness of the region to use for innovative purposes the sources and size of financial resources, profit, cash flow, financial planning, reporting status. The financial resources required in the process of creation and, in particular, the diffusion of innovations, certainly deserve special attention in this classification. In this regard, most regions of Ukraine are not only deprived of the possibility of using loans for innovative purposes, but often do not have their own funds even to carry out basic work to maintain the achieved level of production.

The potential of the region's information base is the ability and readiness of the region to use a communication system for innovative purposes, timely, reliable, sufficient, targeted information systems for collecting, processing and transmitting information, the possibility of encoding, and the relevance of information. An effective innovation process is unthinkable without access to information about the state of the venture capital markets, technologies, inventions, licenses, "knowhow", that is, without appropriate information resources.

Natural resource potential is the ability and readiness of the region to use resource and raw material for innovative purposes, the state of forestry, the number of pastures, roads, disturbed land, resource reserves, costs, and protection of natural resources.

The static component of innovative capabilities is a currently existing time innovative ability and the willingness of the region, dynamic component means capabilities and readiness to innovation. A feature of the dynamic component is its relationship with the strategy and tactics of developing static elements of potential, including material, financial and other types of resources.

In our opinion, this composition can represent the innovation potential of any subject of innovation activity, including the regional socio-economic system.

Along with such generally accepted structural elements of innovation potential as material, personnel, financial, investment and management system potential, we distinguish such elements as institutional, image, and external environment.

It should be noted that such a resource as the external environment does not belong to the region, and the full subjects of management of this resource are forces located outside the region. However, we believe that these circumstances cannot be the reason for ignoring this resource, excluding it from the process of forming and using the innovative potential of the socio-economic system.

Our view of this problem touches on the issues of strategic management, which is particularly emphasized by the inclusion of the external environment in the dynamic component.

In the economic literature and in practice, the external environment is considered as a factor affecting the market potential of the region, and its impact is recommended to be taken into account when managing market potential. In our opinion, the fundamental differences dictate the need to 
consider the external environment of the region as an element of its innovation potential.

The external environment as a factor affecting the innovation potential of the region may or may not be taken into account, but the potential, considered as an integral system, does not change from this: only its output parameters change for better or worse. On the other hand, if the external environment is considered as an equal component of the innovation potential of the region, then ignoring it deprives the system of integrity. Therefore, this provision qualitatively changes the structure of the innovation potential of the region, creating new methodological opportunities for determining the ways of its development and use.

The reason for this conclusion is also the fact that any of the regions is included in the system of interregional, and, at the present stage of development, international relations. Therefore, at present, each region uses the opportunities provided by the external environment to a greater or lesser extent, and counts on their use, forms appropriate programs for this purpose. Thus, the above proposal reflects the need to legitimize the status quo, and the consideration of the external environment as an element of the structure of the innovation potential of the region allows us to purposefully use the relationships existing between the elements of the innovation potential of the region, thereby increasing its effectiveness.

Institutional component of the innovation potential is unique because experience shows that in a market economy, effective use of achievements of science and technology, the use of intellectual capital is possible only under condition of presence in a particular state of a balanced, clear and effective legal basis and creating the necessary institutional organizations, providing innovation related services.

Another component that we have introduced into the innovative potential of the region is the image potential. The role of this potential component is difficult to overestimate, since a positive image of a particular region among potential users is the key to success in promoting its product. In our example, this means that the formation in the minds of business entities of a favorable image of a particular region as a territory where all the necessary conditions for fruitful creativity are created, contributes to the rapid increase in the region of the main component of the innovative potential - the potential of personnel.

Each of the subjects of innovation activity operating in the region has at its disposal the following elements of innovation potential: resources; management system; personnel activities; industry structure; environmental factors.

\section{Conclusions}

The determinant of the sustainable development of the regional socio-economic system in modern conditions is not so much the creation and increase of innovative and technological potential as such, but, firstly, the use of existing potential, and secondly, its increase in those areas that can provide real socio-economic returns. However, in order to ensure the effective use of the innovative potential of the region, it is necessary to determine its content.

The interaction of independent system elements of innovation and technological potential forms a synergistic effect of the region's activities and sustainable development. At the same time, the proposed classification of the components of the innovation potential allows us to focus on its priority elements in specific periods.

This classification of the components of innovation and technological potential is of great practical importance. It focuses the attention of researchers and users on the simple fact that the key element of the innovation potential of the region is the subjects of innovation activity operating on its territory. In particular, among all subjects of management, both employed and not employed population in the market sector of the economy should be singled out.

\section{References:}

Heiets, V. (2014). Modernization in the system "society - state - economy. Journal of European Economy, t. 13, no. 2, pp. 111-124.

Kachala, T. M. (2011). Modernization as a necessary condition for economic reconstruction. Volyn Institute of Economics and Management, vol. 2, pp. 163-171.

Filipenko, A. (2000). Modernization of Ukraine's economy in the context of globalization. Bulletin of the NAS of Ukraine, vol. 1, pp. 34-43. 
Tulchynska, S. O. (2009). Intellectual and innovative modernization of the economy of Ukraine: theoretical and methodological aspects: monograph. Kyiv: NTUU "KPI", 488 p.

Polyakova, A. G. (2009). Conceptual bases of modernization of economy of regions. Bulletin of Tomsk State University, vol. 323, pp. 273-279.

Dunaiev, I. V. (2015). Modernization of regional economic policy: identification and semantic analysis of the conceptual apparatus. Actual problems of public administration. Odesa: ORI NAPA Publishing House, vol. 4(64), pp. 16-20.

Mikhalchenko, M. (2005). Political reality in Ukraine: transformation, modernization, revolution? Modern Ukrainian politics. Politicians and political scientists about her. Kyiv, vol. 7, pp. 18-27.

Petryna, M. (2016). Basic conditions for creating an innovative model of economic development of Ukraine. Ukraine Economy, vol. 48, pp. 35-47.

Lambooy, Jan G. (2001). Evolutionary economics and regional policy. The Annals of regional Science, vol. 35, pp. 113-131.

Human Development Report (2010). The Reak Wealth of Nations: Pathways to Human development. 